University of Nebraska - Lincoln

DigitalCommons@University of Nebraska - Lincoln

May 1991

\title{
PREDICTION OF BREEDING VALUES FOR TWINNING RATE AND OVULATION RATE WITH A MULTIPLE TRAIT, REPEATED RECORDS ANIMAL MODEL
}

L. Dale Van Vleck

University of Nebraska-Lincoln, dvan-vleck1@unl.edu

K. E. Gregory

U.S. Department of Agriculture, Clay Center, NE

S. E. Echternkamp

U.S. Department of Agriculture, Clay Center, NE

Follow this and additional works at: https://digitalcommons.unl.edu/animalscifacpub

Part of the Animal Sciences Commons

Van Vleck, L. Dale; Gregory, K. E.; and Echternkamp, S. E., "PREDICTION OF BREEDING VALUES FOR TWINNING RATE AND OVULATION RATE WITH A MULTIPLE TRAIT, REPEATED RECORDS ANIMAL MODEL" (1991). Faculty Papers and Publications in Animal Science. 244.

https://digitalcommons.unl.edu/animalscifacpub/244

This Article is brought to you for free and open access by the Animal Science Department at DigitalCommons@University of Nebraska - Lincoln. It has been accepted for inclusion in Faculty Papers and Publications in Animal Science by an authorized administrator of DigitalCommons@University of Nebraska - Lincoln. 


\title{
PREDICTION OF BREEDING VALUES FOR TWINNING RATE AND OVULATION RATE WITH A MULTIPLE TRAIT, REPEATED RECORDS ANIMAL MODEL 1
}

\author{
L. D. Van Vleck ${ }^{2}$, K. E. Gregory ${ }^{3}$ and S. E. Echternkamp ${ }^{3}$
}

U.S. Department of Agriculture, Clay Center, NE 68933

\begin{abstract}
A genetic correlation near unity between ovulation rate in heifers and later twinning frequency led to consideration of using measures of ovulation rate in heifers for each estrous cycle, beginning at puberty, to increase accuracy of selection for twinning rate. An initial evaluation with a multiple trait animal model for predicting breeding values included six genetic groups: 1) selected Scandinavian bulls, 2) transfers from other populations at the Research Center to a twinning project, 3) early-purchased Holsteins, 4) late-purchased Holsteins, 5) early purchases-other breeds, and 6) late purchases-other breeds. For ovulation and twin measures, heritabilities of .100 and .070 and repeatabilities of .120 and .092 were assumed. Assumed phenotypic correlation between ovulation and twin measures of .08 was accounted for by genetic correlation of .89 and permanent environmental correlation of .19. The number of animals evaluated was 1,$745 ; 6,912$ estrous cycles were measured for ovulation rate on 840 heifers and 1,929 parturitions were observed for occurrence of twinning on 851 cows, of which 346 had ovulation rate measured as heifers. The remaining 400 animals were foundation animals that created relationships among those with records or were sires of animals with records. The Scandinavian genetic group effect was substantially greater than that of the others. Joint evaluations were compared to evaluations using only twinning measures. For animals with twin evaluations based only on parents but with ovulation rates measured, the multiple trait evaluation increased accuracy of evaluation from .62 (twin information only) to .81 . With one parturition, multiple-trait evaluation increased accuracy from .84 to .92 . Correlation of multiple trait evaluation of ovulation rate with single trait evaluation was .71 for cows with no parturitions and .87 for cows with one parturition.
\end{abstract}

Key Words: Reproduction, Twinning, Cattle, Breeding Value

J. Anim. Sci. 1991. 69:3959-3966

Introduction

Twinning rate in cattle has both advantages and disadvantages (Gregory et al., 1990a,b)

\footnotetext{
$1_{\text {Published as Paper No. 9380, Journal Ser., Nebraska }}$ Agric. Res. Div., Univ, of Nebraska, Lincoln 68583-0908.

${ }^{2}$ Roman L. Hruska U.S. Meat Anim. Res. Center, ARS, USDA, A218 Animal Sciences, Univ. of Nebraska, Lincoln 68583-0908.

${ }^{3}$ Roman L. Hruska U.S. Meat Anim. Res. Center, ARS, USDA, Clay Center, NE 68933.

Received October 1, 1990

Accepted May 6, 1991.
}

and in theory is a difficult trait to improve by selection. Only females can be measured and only relatively late in life. Heritability is low, probably less than $10 \%$. Twinning frequency can be measured at best only once per year and only after 2 to $3 \mathrm{yr}$ of age. Thus, selection for twinning rate suggests the use of information on all relatives to predict breeding value. Effectiveness of selection for twinning rate also would be expected to improve by use of a trait having a large genetic correlation with twinning rate that can be measured at a relatively young age. Echternkamp et al. (1990) suggested using ovulation rate as a correlated trait and began measurement of 
ovulation rate to determine whether ovulation rate could be used to select indirectly for twinning rate. Ovulation rate can be measured several times for each heifer beginning at puberty until first breeding and measured approximately every 21 d. Heritability of ovulation rate in heifers seems slightly larger than heritability of twinning rate (Echtemkamp et al., 1990; Van Vleck et al., 1991). Echternkamp et al. (1990) also pointed out that repeated measurements on the same animal should increase the effective heritability of mean ovulation rate. Because twin ovulations generally must precede twin births, the intuitive conclusion is that ovulation rate is a major contributing factor to twinning rate and should be highly correlated with twinning rate. Van Vleck et al. (1991) with analyses using an animal model obtained results that suggest the genetic correlation between ovulation rate in heifers and twinning rates in subsequent parturitions is .80 to .90 . Theoretical calculations suggest that using ovulation rate in heifers for indirect selection can increase genetic change in breeding values for twinning rate by 150 to $250 \%$ depending on the genetic correlation compared with selection using only frequencies of twinning at parturition.

The next step was to develop a procedure for incorporating ovulation rates measured in heifers and twinning rates for all parturitions into a multiple trait genetic evaluation with an animal model and with all numerator relationships considered. The purpose of this paper is to describe that development and to report the results in terms of estimates of genetic selection group effects, ranges of predicted breeding values, and accuracies based on approximate variances of prediction errors.

\section{Methods}

The first step was to decide how to incorporate the measures of ovulation rate into the model. The original idea was to use the average of measures of ovulation for a fixed number (e.g., eight) of consecutive estrous cycles of puberal heifers. A single measure of ovulation rate per heifer, the average for a fixed number of cycles, seemed computationally to be the simplest way to handle the measurement question. The genetic correlation with twinning rate also has been estimated to be about .90 (Van Vleck et al, 1991). A major disadvantage is that not all heifers had measurements for eight estrous cycles, particularly in the first years of measuring ovulation rate. Adjustment for different heritabilities and variances for averages with different numbers of measurements did not seem simple. In addition, twinning rate would be measured at each parturition with different year and age effects each time so that a repeated records model seemed appropriate for parturition data. Another possibility was to consider the measurement at each estrous cycle a separate trait. The genetic and environmental variancecovariance matrices would be needed but would be of larger or smaller order, depending on how many estrous cycles were measured. Measurements taken $21 \mathrm{~d}$ apart would not seem to define distinctive traits nearly as well as, for example, lactation yields after first, second, or later parturitions. Results from Van Vleck et al. (1991) did not show any differences in correlations between adjacent or nonadjacent cycles. As will be seen, a repeated measurements model for measurement both of ovulation rate and of twinning rate is relatively easy to apply and does accommodate any number of measurements of either ovulation or twinning frequency. Thus, the repeated records animal model was chosen.

Although measurements for both traits are essentially binomial ( 1 or 2 with few $3 \mathrm{~s}$ ), a linear model rather than a threshold model was used. If the underlying distribution is bivariate normal, a bivariate threshold model would be more appropriate. Analytical procedures for threshold model with multiple traits, each with both genetic and permanent environmental effects, have apparently not been developed. Simulation studies for a single trait, single random variable, sire model indicate that, in the absence of fixed effects, ranking of sires was similar for use of a linear or a threshold model for heritability on the normal scale and incidence corresponding to this population (Meijering and Gianola, 1985). For ovulation and twinning measures, effects of levels of fixed factors are not great so that heterogeneity of variance within fixed factors is minimal. $R$. L. Quaas (personal communication, 1989) suggested that the threshold model may not have much advantage over the linear model except when levels of fixed effects are substantially different as for calving difficulty measured on heifers or mature cows.

Genetic groups with effects due to accumulated selection were assigned to be the same 
for ovulation rate as for twinning rate, although the selection of foundation animals was based only on perceived twinning rate. This way of assigning groups made setting up the prediction equations much easier than making separate assignments. Animals that were selected for the project were assigned to six selection groups (after the first evaluation, a seventh group was added as will be described later). Group 1 consisted of five bulls that furnished semen for the project. These bulls had proofs for twinning rate in Sweden or Norway and are called the Scandinavian group. Group 2 consisted of 213 animals that were transferred from other projects at the Research Center (MARC transfers) and was made up of cows that had a history of giving birth to twins plus two bulls that had sired daughters with a high frequency of twins. In evaluations after the first, those two bulls were assigned to Group 7 because the accuracy of their initial selection was much greater than for cows. Group 3 consisted of 13 Holsteins purchased early in the project (1976 to 1977) based on a history of twinning. Group 4 consisted of 21 Holsteins purchased later in the project (1981 to 1982). Groups 5 and 6 were 18 and 33 animals of all other breeds purchased early or late in the project.

Other fixed factors in the model for ovulation rate were birth group of the heifer (year and spring or fall season), age in months at measurement of ovulation $(\leq 11$, $12-13,14-15,16-17, \geq 18 \mathrm{mo}$ ), and calendar month of measurement. For twinning rate, the other fixed effects were year-season of parturition and age in years at parturition (year of parturition minus year of birth, corresponding to $2,3,4, \geq 5 \mathrm{yr}$ ).

$\mathrm{G}_{0}=\quad\left[\begin{array}{ll}\sigma_{\mathrm{g}_{\mathrm{ov}}}^{2} & \sigma_{\mathrm{g}_{\mathrm{ov}} \mathrm{g}_{t w}} \\ \sigma_{\mathrm{g}_{\mathrm{ov}}, \mathrm{g}_{\mathrm{tw}}} & \sigma_{\mathrm{g}_{\mathrm{tw}}}^{2}\end{array}\right]=\left[\begin{array}{ll}.0120 & .0082 \\ .0082 & .0070\end{array}\right]$;

permanent environmental,

$\mathrm{C}_{\mathrm{o}}=\left[\begin{array}{l}\sigma_{\mathrm{p}_{\mathrm{ov}}}^{2} \\ \sigma_{\mathrm{p}_{\mathrm{ov}}, \mathrm{P}_{\mathrm{tw}}}\end{array}\right.$
Random effects for both ovulation rate and twinning rate were additive genetic and permanent environmental (including non-additive genetic) effects of the cow or heifer and temporary, uncorrelated environmental effects associated with each measurement. The variance-covariance structure was based on phenotypic variances of .1200 and .1000 for ovulation rate and twinning rate, heritabilities of .10 and .07 with a genetic correlation of .89 , and permanent environmental variances making up fractions of .020 and .001 of phenotypic variances with a permanent environmental correlation of .19. Temporary environmental effects were assumed uncorrelated between ovulation rate and twinning rate measurements. A phenotypic correlation of .08 results from the genetic and permanent environmental correlations. These parameters were chosen based on estimates from analyses of data from animals borm in the project (Echtemkamp et al., 1990; Gregory et al., 1990a; Van Vleck et al., 1991). Exceptions, which are somewhat arbitrary, were 1) the permanent environmental variance for twinning was set to be slightly larger than zero, $.1 \%$ of phenotypic variance, whereas the analyses suggested zero, and 2) a small covariance between permanent environmental effects for ovulation and twinning rates was also chosen despite the lack of estimates for that covariance to account for some phenotypic covariance not accounted for by genetic covariance. Thus, the variance-covariance matrices for ovulation rate (ov) and twinning rate (tw) were: additive genetic, 
and temporary environmental,

$$
R_{o}=\left[\begin{array}{ll}
\sigma_{e_{o v}}^{2} & \sigma_{e_{o v}, e_{t w}} \\
\sigma_{e_{o v}, e_{t w}} & \sigma_{e_{t w}}^{2}
\end{array}\right]=\left[\begin{array}{rr}
.1056 & 0 \\
0 & .0920
\end{array}\right] ;
$$

so that, phenotypic variance-covariance matrix

is

$$
P_{o}=\left[\begin{array}{ll}
\sigma_{o v}^{2} & \sigma_{o v, t w} \\
\sigma_{o v, t w} & \sigma_{t w}^{2}
\end{array}\right]=\left[\begin{array}{ll}
.1200 & .0085 \\
.0085 & .1000
\end{array}\right] .
$$

To simplify the final form of the mixed model equations (MME, Henderson, 1963, 1973, 1975), measures of ovulation rate were standardized to have the same variance as twinning rate by multiplication of each measure of ovulation rate by $\sigma_{\varepsilon_{\mathrm{tw}}} / \sigma_{\mathrm{e}_{\mathrm{ov}}}=.9334$.

Then to make the final form simpler, as is usually done for single trait equations, both the left and right hand sides of the equations were algebraically multiplied by $\sigma_{e_{t w}}^{2}$. This simplifies setting up the equations but does require adjustment of the elements of the MME due to $\mathrm{G}_{\mathrm{o}}$ and $\mathrm{C}_{\mathrm{o}}$ by pre- and postmultiplication with $\mathrm{T}$ where for $\mathrm{k}=\sigma_{\mathrm{e}_{\mathrm{ty}}} / \sigma_{\mathrm{e}_{\mathrm{ov}}}$

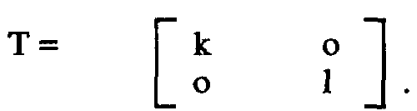

Thus

$$
\left[\begin{array}{ll}
\alpha^{\mathrm{oO}} & \alpha^{\mathrm{ot}} \\
\alpha^{\mathrm{ot}} & \alpha^{\mathrm{tt}}
\end{array}\right]=\left[\mathrm{T} \mathrm{G}_{\mathrm{o}} \mathrm{T}\right]^{-1}
$$

and

$$
\left[\begin{array}{ll}
\lambda^{\mathrm{oo}} & \lambda^{\mathrm{ot}} \\
\lambda^{\mathrm{ot}} & \lambda^{\mathrm{tt}}
\end{array}\right]=\left[\mathrm{T} \mathrm{C}_{\mathrm{o}} \mathrm{T}\right]^{-1}
$$

The method of Westell (1984; Westell et al., 1984, 1988; Quaas, 1988) was used to set up the MME (Henderson, 1963, 1973, 1975) that result from 1) absorbing parents of the base generation that have been assigned to genetic selection groups and 2) applying the Quaas and Pollak (1981) transformation to combine the proper function of estimates of group effects and predictions of additive genetic deviations into the prediction of breeding value.

Then $\mathrm{a}^{*}$ (function of group solutions plus a, the vector of genetic deviations) is the vector of estimated breeding values for all animals including sires and other relatives without records that create relationships. The six (or seven) genetic group effects are included at the end of the " $a *$ " vector to facilitate using the rules of Westell (1984) to compute the coefficient matrix, $W$, associated with breeding values and group effects (similar to those of Henderson [1976] for the inverse of the numerator relationship matrix). Solution vector for ovulation rate is denoted as $a_{0}^{*}$ and that for twinning rate as $a_{t}^{*}$. The vectors correspond to exactly the same animals and assignment of genetic selection groups. Thus, the $\mathrm{W}$ coefficients are the same for the diagonal blocks associated with $\mathrm{a}_{o}^{*}$, with $\mathrm{a}_{\mathrm{t}}^{*}$, and for the upper and lower off-diagonal blocks corresponding to the intersection of the $a_{0}^{*}$ and $a_{t}^{*}$ equations. Similarly the solution vectors for permanent environmental effects are $c_{o}$ and $c_{t}$. For convenience in presenting the MME later, these were set up for all animals and groups in $\mathrm{a}^{*}$ but for animals without records (without both ovulation rate and twinning rate measures) the solutions are always zero as are solutions for the permanent environmental effects associated with the dummy groups. Finally, $\beta_{0}$ and $\beta_{t}$ are solution vectors for the fixed effects that are not genetic selection group effects.

The vectors of observations are $y_{0}$ and $y_{t}$ corresponding to ovulation rate standardized for variance of twinning rate and to twinning 
rate, $X_{0}$ and $X_{t}$ are matrices that associate fixed effects in $\beta_{0}$ and $\beta_{t}$ with $y_{0}$ and $y_{t}$. Similarly, $Z_{0}$ and $Z_{t}$ are matrices associating effects in $a_{a}\left(c_{0}\right)$ and $a_{t}\left(c_{t}\right)$ with $y_{0}$ and $y_{t}$. To facilitate writing the final form of the equations, zero rows are included in $Z_{0}$ and $Z_{t}$ to correspond to animals in $a_{o}^{*}$ and $a_{t}^{*}$ that do not have records (Henderson, 1977) and with extra rows of zeroes in both $Z_{0}$ and $Z_{t}$ to correspond to the genetic group effects. Westell's (1984) W procedure to calculate coefficients due to the inverse of the numerator relationship matrix and the group effects requires a square matrix of the order of the length of $a_{0}^{*}$ or $a_{t}^{*}$.

With all terms now defined, the two-trait, repeated records, $\mathrm{MME}$ are as follows:

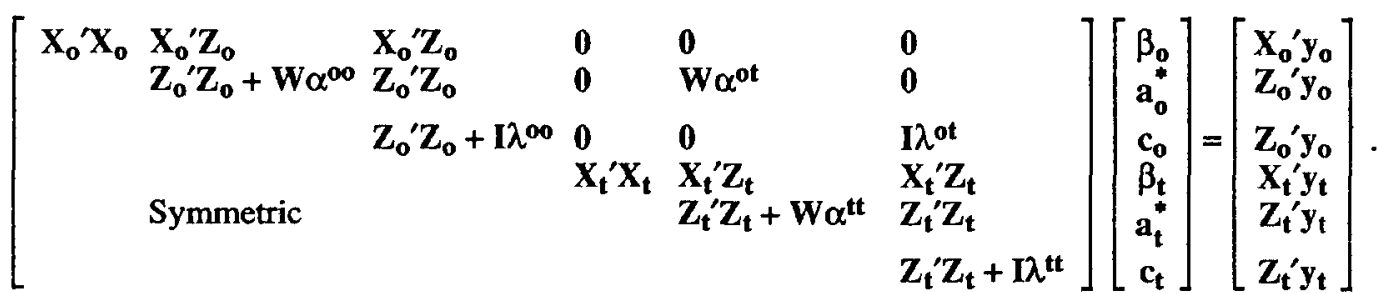

The pattern of the equations written in this order is familiar; blocks comparable to single trait evaluations except for the multipliers of $W$ and I are tied together with off-diagonal blocks corresponding to genetic covariances among genetic effects, $W \alpha^{\circ t}$, and to covariances between permanent environmental effects, $\mathrm{I} \lambda$ ot.

Data for the evaluations reported here include measures of ovulation rate on 6,912 estrus cycles of 840 heifers and measures of twinning rate at 1,929 calvings of 851 cows of which 346 had prior measures of ovulation rate. The remaining 400 animals without records were foundation animals that created relationships among animals with records or were sires. A total of 7,043 equations resulted for the 1,745 animals (with records and without records), 6 genetic selection groups, 25 fixed effects for ovulation rate, and 14 fixed effects for twinning rate. Computer programs were run on a 386-class personal computer with a Weitek coprocessor. Programs to set up the equations were based mostly on major modifications of programs from the DFREML package of Meyer (1988) for single traits. The least modified program was the one normally used to calculate the inverse of the numerator relationship matrix which was modified to calculate the coefficients of $W$. Non-zero coefficients of the MME were stored in memory and solutions obtained by GaussSeidel iteration. Iteration was arbitrarily stopped after 500 rounds. At 500 rounds, the measure of convergence was .00010 , which was calculated as $\sqrt{\Sigma d_{i}^{2} / \Sigma r_{i}^{2}}$ where $d_{i}$ is the difference between the $i^{\text {th }}$ regenerated and actual right hand side, $r_{i}$.

To compare prediction error variances for the two-trait analysis and for using twin records alone, the programs were rerun with $\sigma_{\mathrm{P}_{\mathrm{ov}}, p_{\mathrm{tw}}}=0$ and $\sigma_{\mathrm{B}_{\mathrm{ov}}, \mathrm{g}_{\mathrm{tw}}}=0$. From selection index theory (Henderson, 1963) and properties of MME (Henderson, 1975), the variance of predicted breeding values is, $\mathrm{V}(\mathrm{PBV})=\mathrm{r}_{\mathrm{TI}}^{2}$ $\sigma_{\mathrm{g}_{\mathrm{tw}}}^{2}$ where $\mathrm{r}_{\mathrm{TI}}$ is the correlation between predicted and true breeding value. Because $\sigma_{\mathrm{g}_{\mathrm{tw}}}^{2}$ is assumed known, an estimate of $r_{\mathrm{TI}}$ can be obtained empirically by calculating V(PBV) from actual predicted breeding values. The diagonals of the MME can be used to distinguish non-parents and which non-parents had no (464) or one parturition (164) measured for twinning rate. Non-parents are defined as animals for which no progeny records are known. Then V(PBV) was calculated for those two kinds of non-parents when both ovulation and twinning rates were used and when only twinning rate was used for predicting breeding value.

\section{Results and Discussion}

Predictions of breeding value (PBV) are a function of selection group effects plus a deviation from that function. The function consists of weighting each selection group effect by the fraction of genes of that group transmitted to the animal. The sum of the weights is one. If differences in group effects 
are large, then the result is that a large part of differences in PBV will be due to group effects. Solutions for selection group effects, for twinning rate, in order of group number after multiplying by 100 were: 1) 19.6 and $19.2,2)-2.1$ and $-2.9,3)-1.5$ and $-1.3,4) 1.2$ and $2.4,5)-8.8$ and -8.7 , and 6$)-.3$ and -.8 where the first number is for the two-trait evaluation and the second number is for the evaluation using only measures of twinning rate. In later runs including the second discussed in this and the following three paragraphs, a seventh selection group has been included in the model for two bulls that had been selected from other projects at the Research Center on the basis of twinning frequency of their daughters. Because the accuracy of selection was different for the bulls from that for the selected cows, they were put into a separate group. Considerably more records were also available for the second run of the evaluation programs $(8,617$ equations for 2,136 animals including 1,027 heifers with ovulation rate measured for 8,448 estrus cycles, and twinning rate measured at 3,701 parturitions on 1,356 cows), which may account for some of the changes in estimates of group effects: 1) 17.6, 2) $-6.2,3$ ) 5.0, 4) -8.5 ) $-12.4,6)-2.9$, and 7) 27.3 . The two bulls among the MARC transfers (Group 7) were quite different from the cows that were transferred (Group 2) resulting in a large reduction in the Group 2 estimate.

Differences among the group effects are striking and important in predicting breeding values, which are a weighted average of group effects and a deviation from that average. Thus, the PBV of the five Scandinavian sires assigned to Group 1, based on the second (seven group) analysis, begin with the Group 1 effect of 17.6 as the weight for Group 1 is 1 , whereas animals that trace back to Group 2 with a weight of 1 begin with the Group 2 solution of -6.2 . An animal that traces by .5 to Group 2 (MARC female transfers) and .5 to Group 7 (the two male MARC transfers) would begin with $.5(-6.2)+.5(27.3)=10.55$. Consequently, most of the top ranking animals for PBV trace to Group 1 or Group 7. Included in the top 20 of the PBV for the analysis with seven groups were four bulls; two of the five Group 1 bulls, one of the Group 7 bulls and a grandson of a Group 1 bull. The 16 females in the top 20 all were daughters (12) and(or) granddaughters (5) of those three bulls. In- cluded in the top 30 PBV were another Group 1 bull and the other Group 7 bull.

Of the top 16 ranked females, only seven had given birth. The other nine including the top two overall were ranked high because of information on relatives and high ovulation rates. The top two had unusual ovulation rates. The top one had 20 ovulations and the other 16 ovulations in eight estrous cycles. Included were five and three triple ovulations, respectively. Only one other of the top 16 females had even a single triple ovulation. Triple ovulations were not tabulated on other heifers but a visual examination of the ovulation rate file showed very few. A question might be raised as to whether a rate of three gives too much advantage to the few cows that have triple ovulations.

The top five PBV were 40.4, 35.1, 32.8, 32.1 , and 32.1 and the bottom five PBV were $-15.1,-15.2,-15.3,-15.6$, and -17.0. The animal model evaluation provides an extensive spread in PBV even with measurements of essentially only 1 or 2 .

Crude measures of improvement in accuracy of prediction of breeding value for twinning rate due to use of ovulation rate can be made from comparison of analyses with twin rate alone and twin rate combined with ovulation rate as described in the methods section. With no parturitions measured, the $\mathbf{r}_{\mathbf{T I}}$ values were .62 when twinning rate alone was used and .81 when both twinning and ovulation rates were used. The correlation between the two sets of PBV was .71. With one parturition measured, the $\mathbf{r}_{\mathrm{TI}}$ values were .84 when twinning rate alone was used and .92 when both traits were used. The correlation between the two sets was .87. Accuracy of prediction was substantially improved for both types of animals when ovulation rate was included. The actual improvement may be larger. The selection index theory applies to when the prediction is for the deviation of genetic value from the appropriate group mean. The PBV, however, include functions of estimates of the group effects. Thus,

$$
\begin{aligned}
\mathrm{V}(\mathrm{PBV})= & \mathrm{V}[\mathrm{ftn} \text { (group effects)] } \\
& +\mathrm{V}(\text { deviation) } \\
& +2 \text { Cov [ ftn (group effects) } \\
& \text { deviation]. }
\end{aligned}
$$

The theory applies to $\mathrm{V}$ (deviation) so that $\mathrm{V}(\mathrm{PBV})$ would be larger than V(deviation) by 
the sum of variance of estimates of group effects and twice the covariance between predicted deviation and estimates of group effects. These components could be determined if the inverse of the coefficient matrix were available, but the matrix was too large to invert with available computing facilities. However, the two terms that inflate V(PBV) may be quite similar for the analyses with twinning rate alone and twinning and ovulation rates together because the group solutions are similar for both cases.

\section{Conclusions and Further Discussion}

Computation of multiple trait predictions of breeding value for twinning rate from repeated measures of heifer ovulation rate and twinning rate is not difficult. Empirical evidence and theory suggest accuracy of evaluation is increased substantially when ovulation rate is used. Some questions, however, remain. One question concerns the binomial nature of the records. The mixed model procedure does not depend on normality, whereas expected response does. Will ranking be the same with binomial data as with a threshold model that assumes an underlying normal distribution? Ovulation rate based usually on about eight estrous cycles should behave quite well because of the averaging effect. The differences in means by fixed effect levels are not great (Echtemkamp et al., 1990; Gregory et al., 1990a). Twinning rate is often based on one or two parturitions, although differences in means due to levels of fixed effects also are not great. The MME with the numerator relationship matrix essentially make use of partial replication (i.e., the genes that relatives share provide information on all of the relatives). The result is that the PBV are more nearly continuous than might be thought from applying simple selection index procedures to binomial records. If relationships are not utilized, all animals scored with a 1 would have the same PBV and all scored with a 2 would also be ranked equally in the same contemporary group. Measures in more than one parturition would create a few more discrete classes of PBV. The MME procedure described here that uses the numerator relationship matrix and measures of ovulation and twinning rate resulted in an almost continuous array of PBV with at least one of the 2,136 animals in every percentage class (PBV * 100) from 29 to -17 . The total range was 40 to -17 .

Another question is whether the parameters assumed in the evaluation, especially the genetic correlation and heritabilities, are appropriate. The genetic correlation is most important for animals that have no measured parturitions.

\section{Impllcations}

Multiple trait evaluations using ovulations measured in repeated estrous cycles of puberal heifers and repeated measures of birth rate will increase the accuracy of prediction of breeding value for twinning rate. Selection can also be done earlier because the procedure does not require parturition records. Increased accuracy of prediction and decreased generation interval should increase the rate of genetic progress for twinning in the twinning project at the U.S. Meat Animal Research Center and other projects with similar objectives. Theoretical and empirical increases in accuracy, however, are dependent on the genetic correlation between ovulation and twinning rate.

\section{Literature Cited}

Echternkamp, S. E., K. E. Gregory, G. E. Dickerson, L. V. Cundiff, R. M. Koch and L. D. Van Vleck. 1990. Twinning in Cattle: II. Genetic and environmental effects on ovulation rate in puberal heifers and postpartum cows and the effects of ovulation rate on embryonic survival. J. Anim. Sci. 68:1877.

Gregory, K. E., S. E. Echternkamp, G. E. Dickerson, L. V. Cundiff, R. M. Koch and L. D. Van Vleck. 1990a. Twinning in Cattle: I. Foundation animals and genetic and environmental effects on twinning rate. J. Anim. Sci. 68:1867.

Gregory, K. E., S. E. Echternkamp, G. E. Dickerson, L. V. Cundiff, R. M. Koch and I. D. Van Vleck. $1990 \mathrm{~b}$. Twinning in Cattle: III. Effects of twinning on dystocia, reproductive traits, calf survival, calf growth and cow productivity. J. Anim. Sci. 68:3133.

Henderson, C. R. 1963. Selection index and expected genetic advance. In: Proc. Statistical Genet. and Plant Breeding. pp 141-163. NAS-NRC Publ. 982.

Henderson, C. R. 1973. Sire evaluation and genetic trends. pp 10-41. In: Proc. Anim. Breeding Genet. Symp. in Honor of Dr. Jay L. Lush. ASAS, ADSA, Champaign, II.

Henderson, C. R. 1975. Best linear unbiased estimation and prediction under a selection mode. Biometrics 31:423.

Henderson, C. R. 1976. A simple method for computing the inverse of a numerator relationship matrix used in prediction of breeding values. Biometrics 32:69.

Henderson, C. R. 1977. Best linear unbiased prediction of breeding values not in the model for records. J. Dairy Sci. 60:783.

Meijering, A. and D. Gianola. 1985. Linear versus nonlinear 
methods of sire evaluation for categorical traits: A simulation study. Genet. Sel. Evol. 17:115.

Meyer, K. 1988. DFREML, a set of programs to estimate variance components under an individual animal model. J. Dairy Sci. 71(Suppl. 2):33.

Quaas, R. L. 1988. Additive genetic model with groups and relationships. J. Dairy Sci. 71:1338.

Quaas, R. L., and E. J. Pollak. 1981. Modified equations for sire models with groups. J. Dairy Sci. 64:1868.

Van Vleck, L. D., K. E. Gregory and S. E. Echternkamp.

1991. Ovulation rate and twinning rate in cattle:
Heritabilities and genetic correlation. J. Anim. Sci. 69: 3213.

Westell, R. A. 1984. Simultaneous evaluation of sires and cows for a large population. Ph.D. thesis. Comell Univ., Ithaca, NY.

Westell, R. A., R. L. Quaas, and L. D. Van Vleck. 1984. Genetic groups in an animal model. J. Anim. Sci. 59(Suppl. 1):175 (Abstr.).

Westell, R. A., R. L. Quaas and L. D. Van Vleck. 1988. Genetic groups in an animal model. J. Dairy Sci. 71: 1310. 